\title{
Pau de Tars (10-67): em vaig quedar garratibat
}

\section{Octavi Fullat i Genís*}

\section{Resum}

Aquest article presenta el perfil de Pau de Tars que l'autor no va conèixer fins que va visitar Atenes l'any 1969. Fou llavors quan, acompanyat de la seva germana Maria, es va adonar de la magnitud del missatge paulí, que el va deixar garratibat. Sens dubte, Pau -un cop apartat del judaisme oficial- ha esdevingut el primer gran pensador del cristianisme. De fet, resseguir la ruta que Pau va traçar sobre l'antiga Grècia va propiciar que l'autor s'endinsés en el pensament paulí, un jueu fariseu que després de caure del cavall -una imatge simbòlica- en el viatge a Damasc es va posar al servei del cristianisme. No debades, les cartes paulines són un document fonamental per conèixer la vida de les primeres comunitats cristianes com la de Corint i, sobretot, per endinsar-se en la teologia paulina que anuncien la nova bona -evangeli- de l'esdeveniment de la mort-resurrecció de Crist, una irracionalitat conscient i majestuosa. En qualsevol cas, la resurrecció no es tracta d'una veritat que els historiadors puguin comprovar, sinó d'una veritat existencial i de cap manera verificable. En darrer terme, aquesta resurrecció - un escàndol per a la raó humana- només es pot capir des d'una posició intel.lectual receptiva al misteri de la paraula, a la força del Logos joànic.

\section{Paraules clau}

Pau de Tars, filosofia de l'educació, teologia de l'educació, història de la pedagogia, cristianisme, pensament pedagògic.

Recepció original: 02 de febrer de 2017

Acceptació: 14 de novembre de 2017

Publicació: 20 de juliol de 2018

De nen, d'adolescent, tot al llarg de la meva formació d'escolapi i també a continuació, sant Pau se'm presentava a tort i a dret a les misses, en conferències espirituals, en sermons, en exhortacions del confessionari... Tant afany i vehemència van acabar per banalitzar-me'l i fer que em semblés un autor balder, apte per a velles desdentegades i

${ }^{*}$ C Catedràtic emèrit de Filosofia de l'Educació de la Universitat Autònoma de Barcelona. Doctor Honoris Causa per diverses universitats de l'Estat (Universitat Ramon Llull, 2009) i estrangeres. Posseeix una extensa bibliografia que s'apropa als 140 llibres i que inclou els tres volums de les seves memòries: La meva llibertat (2006), La meva veritat (2008) i La meva bellesa (2010). Aquest article segueix la sèrie que va començar en el núm. 41 (segon semestre de 2011), amb l'aportació «Albert Camus, un perfil personal» i que va continuar en el núm. 43 (segon semestre de 2012), amb la contribució «Aristòtil: la vigència d'un mestre pensador». Més tard, en el núm. 44 (primer semestre de 2013) es va publicar una tercera contribució: «Sigmund Freud: la llum de la posta» i en el núm. 45 (segon semestre de 2013) una quarta amb el títol «Heidegger em va ferir». Durant l'any 2014, es van publicar «Edmund Husserl (1859-1938). Li vaig demanar auxili» en el núm. 46 (primer semestre) i el dedicat a «Immanuel Kant (1724-1804). Sense frivolitats de "Facebook"» en el núm. 47 (segon semestre). Al seu torn, en el núm. 49 (segon semestre de 2015) va aparèixer l'article dedicat a «Karl Marx. El meu apassionament ètic va donar llum a Marx», mentre que en el núm. 51 (segon semestre de 2016) es va publicar el dedicat a «Claude Lévi-Strauss (1908-2009). El discurs gèlid» i, finalment, en el núm. 52 (primer semestre de 2017) s'ha inserit el treball «Friedrich Nietzsche (1844-1900). Del cop vaig quedar estabornit». Amb aquests treballs sobre diferents personalitats del pensament i la cultura, el professor Fullat vol honorar aquells autors que més significativament han influït en la gènesi i evolució de la seva filosofia i que, en conjunt, han donat peu al llibre Impertinentes. El desgarro de pensar (Barcelona, Edicions de la Universitat de Barcelona, 2016). Altra volta agraïm al professor Fullat la seva confiança en permetre que publiquem a les pàgines de Temps d'Educació aquests retrats i perfils, escrits des d'una posició personal i testimonial, no exempta mai d'una agudesa i finor intel-lectual ben remarcables que ajuden a entendre la gènesi i evolució del pensament pedagògic contemporani, i, nogensmenys, la seva gènesi, més encara en el cas de Pau de Tars. 
capellans illetrats o, actualment, per a gent del Facebook. No fou fins el 1969 que Pau de Tars trucà a la porta de la meva curiositat intel.lectual. Era Doctor en Filosofia per la Universitat de Barcelona des del 1961. La meva germana Maria m'havia proposat fer un viatge a Grècia i allà ens vam dirigir aprofitant les vacances d'estiu. Atenes. Corint. Efes.

Vam deixar dalt de l'Acròpolis tres joies majúscules: Temple d'Athena Nike, Parthenon i Erekhtheion amb les seves Cariàtides. Baixant pels Propileus sortim de l'espai majestuós a través de la porta Beulé i, a peu, ens plantem enmig de l'Arios Pagos, I'Areòpag. Mentre érem allí, la Maria, excel-lent professora de llengua i de civilització franceses, s'adona de la presència d'un grup que venia de França per tal de fer-se amb la cultura grega d'altra època. Immediatament hi va establir contacte.

Pau de Tars havia trepitjat les mateixes pedres que nosaltres teníem sota els peus. Va ocórrer a l'any 50 de la nostra era. Succeí durant el seu segon viatge evangelitzador. I la senyora francesa, amb veu convincent va llegir uns paràgrafs dels Actes dels Apòstols:

Pau conversà amb alguns filòsofs epicuris i estoics. Quan va anunciar Jesús i també l'«anastasis»

— «anastasis» es tradueix habitualment amb la paraula «resurrecció» encara que pròpiament significa

«aixecament dels caiguts»—, alguns es preguntaven;

—Què significa aquesta xerrameca?

Altres afirmaven:

—No hi ha dubte que és un predicador de déus estrangers.

En aquest punt, la senyora francesa ens advertí que Anastasis es podia haver entès com el nom d'una divinitat estrangera. El verb grec anistémi, prosseguí la dama, significà «aixecar», «despertar»; ara bé, un cop substantivat podia evocar una personalitat divina d'altres cultures. Jo em notava, cada vegada més abatut. Jo, el professional del cristianisme, ignorava les coses que aquella Professora — després me'n vaig assabentar que ho era- exposava amb la més absoluta normalitat.

La senyora continuà amb el text de Els fets dels apòstols, que és el segon tom de l'obra atribuïda a Lluc, el primer és l'evangeli. Està redactat en una Koiné —el grec comú-que es pot qualificar d'elegant:

Pau, dret al mig de l'Areòpag, digué:

-Atenencs, observo que sou molt religiosos... Tot passejant he trobat fins i tot un altar amb aquesta inscripció: «Al Déu que no coneixem»... És d'aquest Déu que us vinc a parlar.

Aquest Déu va fer el món... i ara té senyalat el dia en què jutjarà l'univers per mitjà de l'home que ha designat, i ha donat a tots garantia d'això ressuscitant-lo després de la mort.

En sentir «resurrecció dels morts», alguns es van posar a riure i altres digueren:

—D'això ja ens en parlaràs un altre dia. Aleshores Pau va sortir del grup.

La professora va fer una pausa, i digué:

—Pau, a Atenes, no va fundar cap grup seu, cap ekklesía o assemblea convocada —el verb grec ekkaleo significà «jo convoco»—.

Llavors no em vaig poder estar de preguntar-li:

—Per quin motiu no va erigir una comunitat cristiana a la gran ciutat d'Atenes?

Tots em van mirar amb curiositat i amb una certa altivesa causada per la meva atrevida intromissió. 
-Pau no va fundar esglésies cristianes. Sàpiga, senyor, que el concepte de cristianisme encara no s'havia elaborat. Responent a aquesta qüestió, vostè hauria de saber que Atenes fou la seu del logos, de la philosophia. Pau predicava una antifilosofia.

Discretament la meva germana Maria i jo ens vam allunyar deixant el camp lliure.

L'apologètica que m'havien inculcat presentava la fe amb raons. Aquestes raons havien de defensar, justificar, la creença religiosa. El terme grec apologia volia precisament dir «defensa», «justificació». M'acabaven de dir que fe - pistis- i raó - logos- constitueixen postures intel.lectuals oposades; sant Pau estava situat al costat de la $f e$, de la pistis, mentre que Plató i Aristòtil i Euclides i Arquímedes se situaven al costat de la raó -logos-. M'havien clavat un bon contratemps al cor de l'existència, de la meva existència; ¿que potser només es pot abraçar la fe religiosa si s'és neci, totxo o tocat de l'ala?

Des que a la Universitat de Barcelona em van voler aclarir el concepte de logos, sempre he tingut la impressió que es tractava d'un terme enrevessat, probablement polisèmic. El verb grec legein significava originàriament: «reunir», «agafar», «escollir». Així vaig llegir a la llíada:

Ostea legomen — «recollir els ossos»—.

Però, aviat s'emprà logos en el significat de «paraula» i de «discurs». Logos ja va ser «el poder del discurs» $i$ «la rectitud d'allò que es diu». Així, per exemple, en el Gòrgies de Plató. La dialèctica platònica consistia en l'art de formular preguntes correctes i de proporcionar bones respostes a aquestes preguntes. D'aquesta manera logos, un discurs argumentatiu, s'oposava a mythos, simple discurs narratiu. Logos implicava no tan sols enunciar, sinó també justificar. En el seu dia vaig meditar el Theaitetos de Plató, particularment els versets 201 e-202 c:

Aquell que no és capaç de donar o de rebre la justificació del discurs és un ignorant.

Sant Pau, si anés desproveït de logos, fora en conseqüència un ignorant, un vulgar predicador del mythos. Però tot plegat no em resultà tan simple ja que hi havia el mot logos emprat per sant Joan — fos qui fos, aquest - tant a l'inici del quart evangeli on fa servir quatre vegades el terme logos - els textos neotestamentaris estan redactats en llengua grega - com en la seva primera carta, on en dues ocasions fa servir la paraula logos i a l'Apocalipsi, llibre en el qual logos apareix una vegada. Els escrits de Pau de Tars són anteriors a la resta de textos del denominat Nou Testament, tot i això cal suposar que Pau no desconeixia el corrent de pensament gnòstic, hel-lenístic, que havia concretat aquest significat quasi místic del significant logos.

Ara bé, si acceptem l'ús que Plató fa de logos, l'evangeli -eu, «bon»; angelion, «anunci»—, l'evangeli de sant Pau és el mythos d'un embogit, d'un insensat.

Després de la nostra estada a Atenes llogàrem un cotxe i la meva germana i jo vam anar a Corint. M'interessaren l'Arhea Kórinthos i l'Akrokórinthos. Duia amb mi un Nou Testament de butxaca. Pau havia estat a Corint a l'any 50 després del fracàs d'Atenes i hi va residir un any i mig. Asseguts tots dos a l'àgora em va semblar encertat llegir la seva Primera carta als corintis, missiva que havia escrit a Efes o Ephesos, població en la qual va residir també per espai de dos anys i mig, gairebé tres. Va ser a la primavera de l'any 56 quan redactà l'epístola. 
El primer capítol de la carta, d'antuvi em va sorprendre, però en iniciar el segon em vaig quedar garratibat. Jo llegia en veu alta mentre la meva germana escoltava amb deferència:

\footnotetext{
Vaig venir a la vostra ciutat per anunciar-vos el designi de Déu i portar-lo a terme sense cap mena d'escarafalls o de saviesa.

No he pretès mai saber altra cosa que Jesucrist i a aquest crucificat.

M'he presentat a vosaltres feble, espantat i tremolant de por.

El meu llenguatge i el meu crit no van ser savis i persuasius discursos, sinó més aviat una mostra del poder — «dynamis»— del buf o alè — «pneuma»— perquè no us fiéssiu del saber humà sinó de la potència, o intensitat, de Déu.
}

—iBrutal, terrible! — vaig dir-li a crits a la Maria, la meva germana, que va posar uns ulls esbatanats davant les meves exclamacions.

Des de la part alta del recinte, les ruïnes del Temple d'Apol.lon, que havien escoltat la veu de Pau, ens van mirar ertes, impassibles i pàl-lides.

-Per què, Octavi, tant d'enrenou?

-Perquè: o fe o bé raó. L'una escup l'altra. El savi no pot creure, almenys en tant que savi: si ho fa, renega del saber.

Pau havia renunciat a la Llei jueva perquè no salvava, sinó que feia esclau. Pau es negava a ingressar en la sophia, en el logos, en la saviesa grega, perquè era ciència humana i l'home no pot rescatar l'home.

Com quedava? doncs abraçat a Jesucrist, sustentat sobre el pneuma, o buf; sostingut per la dýnamis, o força de Déu. En certa manera, tekhne divina contra episteme humana. No sortia de la meva estupefacció. Creure en Déu, i en allò que una tal convicció arrossega amb si mateixa, moral inclosa, exigia menystenir, reduir i àdhuc negar el valor del coneixement. Pathos, sí; Wille kantiana, o voluntat, també. En canvi, la ciència, la Wissenschaft alemanya, queda desterrada del fet religiós, roman expatriada de la fe, de la emunah o hemeth, de la pistis grega, de la fides llatina. ¿Que potser tenia raó Luter? ¿estaria encertat Kierkegaard? ¿Credo quia absurdum? ¿existència en contra de raó?

Per a Pau, la fe en I' "esdeveniment-Crist» - la seva crucifixió i resurrecció- era la dimensió historicista essencial; portava el desxiframent de la temporalitat. Ell visqué de la fe. Pau llegí la realitat, no pas com a coneixement, sinó a manera de discerniment dels signes de salvació a venir que la realitat inclou.

Vaig informar a la Maria que jo continuava llegint la Primera carta als corintis. Ella es va estimar més recórrer l'Arhea Kórinthos: Temples d'Octavi i d'Apol·lo, Font Sagrada, Font Pirene i la resta de l'àgora.

Tornant enrere en la meva lectura vaig descobrir que m'havia precipitat llegint el primer capítol. Heus aquí el que descobreixo amb estupor:

¿Que potser Déu no ha demostrat que la saviesa d'aquest món és bogeria?...

El món no va reconèixer Déu a través del saber; per això Déu va voler salvar, amb la bogeria del Crist, aquells que s'hi entreguen amb confiança. 
Els jueus exigeixen senyals i els grecs demanen saviesa; però nosaltres cridem, a tots, un messies crucificat. Això és un escàndol per als jueus i és una estupidesa per als savis. Per a aquells que s'entreguen, en canvi, la bogeria de Déu és més sàvia que la humanitat i la feblesa és més forta que la humanitat...

El més plebeu del món, allò menystingut, Déu ho ha escollit per a ell: el que no existeix, a fi d'anul-lar allò que existeix.

He d'advertir que aquestes línies les vaig redactar a finals de 2014; han fugit molts anys des d'aquell matí de 1969 en què vaig devorar el text de Pau, assegut a l' Arhea kórintos. Ara, quan escric, no $\mathrm{m}$ 'he refiat de la versió que vaig utilitzar en aquella ocasió beneïda. En aquest moment he anat al text grec i a la traducció francesa de La Bible Bayard (París, 2001).

L'escrit de Pau és una irracionalitat conscient, que goso qualificar de majestuosa. Per exemple en el capítol 15:

Si els morts no s'han aixecat, tampoc Crist no s'ha despertat i si Crist no s'ha despertat, la nostra paraula es vana i la nostra confiança també. Fins i tot seríem uns falsos testimonis de Déu.

Si els morts no es desperten, tampoc Crist no s'ha despertat. I si Crist no s'ha despertat, la nostra confiança no és res més que il.lusió, i vosaltres continuareu sense haver-vos salvat de la falta, de la insuficiència.

Creure en la resurrecció dels morts i, en conseqüència, de Crist és per fer riure a qualsevol que tingui els cinc sentits. La fe religiosa no és cosa de raó, sinó de demència i d'alienació. Més endavant, no en aquell matí acaronat per les ruïnes de la vella Corint, he meditat sobre el valor de la bogeria - mania, aphrosyne, paranoia, en grec-. El significant presentà ben aviat dos significats: el positiu -entesa, la bogeria, com a potent entusiasme- i el negatiu — compresa a manera de desraonament absolut- - La manía grega i el fúror llatí assenyalen estats excepcionals de força inaudita; en canvi, l'aphron grec i la insania llatina fan referència a la pèrdua de la raó, de logos, de ratio. El Fedre de Plató ja va plantejar les dues maneres d'intel.ligir el terme bogeria, la sensata i la insensata. ¿Com hem d'entendre la bogeria dels escrits de Pau de Tars? Això em va apassionar força temps. Era quelcom crucial per a mi. Déu i intel.ligència lluitaven a mort; o un, o bé l'altra. Immanuel Kant a la seva Kritik der reinen Vernunft va fer llum en aquesta qüestió; li ho agrairé sempre.

La bogeria de Pau ¿és la sensata o bé la insensata? si em fio del text grec de la Primera carta als corintis no es pot negar que la bogeria que Pau predica constitueix un procedir radicalment oposat al logos, a la ratio. Va escriure amb contundència com ja he indicat:

La bogeria de Déu és més sàvia que els homes $(1,25)$.

En el seu grec de la koiné, tot i que amb la nostra grafia:

Oti to moron ton Theou sophóteron ton anthropon estin $(1,25)$.

I a la traducció llatina de sant Jeroni:

Quia quod stultum est Dei, sapientius est hominibus $(1,25)$.

A la mateixa epístola podem llegir:

Si algú entre vosaltres es creu savi ara i aquí, que esdevingui boig $(3,18)$.

I amb el seu grec; només el final de l'asseveració:

morós genesthó $(3,18)$. 
I a la traducció de sant Jeroni; sols el final:

stultus fiat $(3,18)$.

I encara un altra cita d'aquesta carta als corintis:

Nosaltres som bojos a causa de Crist $(4,10)$

En el seu grec; únicament la primera part:

emeis moroi $(4,10)$

En el llatí de Jeroni (347-420):

nos stulti $(4,10)$

Pau es va valer del mot grec moria - «bogeria»- a fi de qualificar la seva entrega a Crist, a l' «Esdeveniment-Crist». Crucifixió i resurrecció de Crist: una bogeria en la vida de Pau. El poeta tràgic grec Aiskhylos -Èsquil- (525-456 aC.) va emprar el terme moria — «bogeria», «insensatesa», «niciesa»- com ho féu també el filòsof Plató; moria, estava Iligat al verb moraino - «ser boig», "ser o dir de manera nècia», «tornar-se boig, insípid, insensat»- La Vulgata de sant Jeroni traduí moria per stultitia. M'inclino a pensar que Pau va escriure moria en el seu significat d'allò radicalment oposat a Logos, a Ratio, a Vernunft, a Reason, a Ragione, a Razón, a Raó.

Pau de Tars començà a ser estimulant per a la meva intel.ligència, tan incitant com ho han estat Descartes o Camus, o Kierkegaard.

Continuem, la Maria i jo, el nostre recorregut amb el cotxe llogat: Micenes, Epidaure, Mistras, Olímpia i en ferry passem a l'Àtica des del port de Patràs. Delfos i Meteores. Això comportà uns dies. De retorn a Atenes, vam sortir del port del Pireu per conèixer Creta, Rodes, Patmos i esplaiar-nos a Efes.

La població que m'interessava d'Efes era la de l'època romana; Pau hi havia viscut per espai de tres anys, probablement des del 54 al 56. Ciutat a la costa occidental de I'Àsia Menor, actualment dins de l'Estat turc. Els jonis I'havien colonitzat al segle XI aC. A l'any $129 \mathrm{aC}$ ja es converteix en la gran metròpoli romana d'Àsia. Situada entre Esmirna i Milet. La seva població assolia la xifra de 200.000 habitants. Port marítim tant cap a Grècia com vers la península italiana. Hi destacava el temple dedicat a Artemisa, la Diana dels romans. També la seva biblioteca fou importantíssima, tan considerable com la de Pèrgam i la d'Alexandria.

En aquest centre urbà hi vivia una comunitat jueva nombrosa. No és estrany, doncs, que Pau intentés predicar el seu evangeli a les sinagogues.

En un dels nostres dies d'estada a Efes vaig voler llegir la carta, atribuïda a Pau, dirigida als efesis; ho vaig fer assegut davant l'esplendorosa façana de la biblioteca que conserva encara la seva majestat. Segurament Pau de Tars hi devia haver entrat més d'una vegada. Un simple supòsit, atesa la seva formació filosòfica a Tars.

Després vaig saber que l'epístola als convocats d'Efes no la redactà sant Pau, sinó algun deixeble d'ell. Tot fa pensar que es va escriure entre l'any 70 i el 100, i ens consta que Pau havia estat decapitat, a Roma, I'any 67. 
En un bell matí d'estiu em vaig submergir en la seva lectura. En cap moment em vaig sobresaltar; es tracta d'un redactat tranquil i harmònic que no em produí cap trasbals ni cap inquietud. Heus aquí un passatge que se m'antullà poètic:

\footnotetext{
M'agenollo davant el Pare, aquell que dóna el seu nom tant al cel com a la terra, i li prego que, per la riquesa de la seva glòria, consolidi amb la força del seu Esperit el que sou en el vostre interior; que per la fe, faci habitar el Crist en els vostres cors i així fonamentats en l'amor sigueu capaços de comprendre amb tots els escollits, I'amplada i la llargada, l'alçada i la profunditat de l'amor de Crist, el qual amor sobrepassa tot coneixement i, així, entreu del tot a la plenitud de Déu.
}

Mythos!, vaig exclamar en solitari ja que la Maria es passejava per les restes arqueològiques. Mythos, a la Grècia clàssica, significà relat no verificable en oposició a Logos. A la llíada d'Homer, mythos designà la «paraula expressada» oposada a ergon, «acte realitzat». Plató en el diàleg Phaidon —Fedó- distingeix entre mythos, «relat inventat pel poeta», i logos, «discurs argumentatiu». El mite va ser un missatge, abocat en forma de relat, amb el qual una generació transmet a les generacions següents allò que cal guardar a la memòria per mantenir-se col-lectivament vius; és a dir, amb sentit a fi de continuar existint com a éssers humans. El logos emet enunciats dels quals se'n pot verificar la seva adequació a la realitat apuntada; el mythos, en canvi, parla de realitats que s'han d'admetre com a existents, però que ni les percepcions ni l'intel-lecte poden provar.

Pau de Tars es planta en el terreny del mite i es gira d'esquena als discursos argumentatiu i verificador. Després de tant sant Pau a tort $i$ a dret, he de confessar que no va ser fins al feliç estiu de 1969 quan l'imponent Paulos de Tars entrà a la meva vida intel.lectual sacsejant-la amb violència. ¿Desmesura meva aquesta manera de parlar de Pau? Altres, més valuosos que no pas jo, s'han hagut d'afrontar amb aquest personatge singular: Agustí de Tagaste, Luther, Pascal, Hegel, Comte, Nietzsche, Freud, Heidegger, Barth, Lacan, Adorno, Benjamin, Schmitt, Taubes, Urs von Batthasar, Lyotard, Ricoeur, Badiou...

De retorn a Barcelona em vaig sentir impel-lit a fer-me amb la figura, vida i pensament, d'aquell jueu, gairebé renegat, que camí de Damasc, perquè era fariseu fervorós, experimenta de manera sobtada un tomb existencial que li muda la biografia. De perseguidor de jueus herètics es converteix en apòstol de l' "adveniment-Crist». Feia temps que ell hi rumiava: ¿seria, o no, el Messies, el Mashiyah tan anhelat, el Crist d'aquells jueus oficialment herètics? Devia patir una sotragada existencial immensa. Allò de la caiguda del cavall és grafisme literari per tal de fer entendre el gran canvi sofert. Cau del cavall sol; creu en Crist sense cap predicador que el converteixi.

Atrafegat amb les ocupacions acadèmiques i amb altres pensadors en els quals estava treballant, això de Pau es va prolongar durant anys.

El primer problema plantejat fou: ¿com abordar-lo? I el segon: havia de deconstruir el Pau que habitava en mi religiosament si em volia adreçar al Pau pensador. Calia fer una reducció eidètica a l'estil de Husserl i prescindir de la meva vivència religiosa de I'apòstol Pau; si no ho feia així, el resultat de la tasca quedaria contaminat.

Com a treball metodològic previ vaig considerar imprescindible fer-me una bibliografia. 


\section{A. Per als textos de Pau}

Novum Testamentum Graece (text grec original), Nestlé-Aland, Deustche Bibelgesellschaft, 1993.

Biblia sacra iuxta Vulgatam Clementinam (text llatí de la Vulgata de Sant Jeroni), BAC, Madrid, 1946.

La Bíblia (traducció catalana), Associació Bíblica de Catalunya, Claret, Barcelona, 1993.

Nueva Biblia Española (traducció castellana), Ediciones Cristiandad, Madrid, 1975.

La Bible (traducció francesa), Service biblique catholique Évangile et Vie. Bayard, Paris, 2001.

\section{B. Per comprendre Pau}

Badiou, A., Saint Paul. La fondation de l'universalisme, P.U.F., Paris, 1997.

Bart, K., Romerbrief, Theol. Verlag, Zurich. En francès: L'Épître aux Romains, Labor et Fides, 1972.

Breton, S., Saint Paul, P.U.F., Paris, 1988.

Bornkamm, G., Paul, apôtre de Jésus-Christ, Labor et Fides, 1971 (traducció).

Brunot, A., Lettres aux jeunes communautés, Centurion, 1972.

Cerfaux, L., L'itinéraire spirituel de saint Paul, Cerf, 1965.

Cothenet, E., L'épître aux Galates, CE, 34.

Cothenet, E., Paul en son temps, CE, 26.

Gibert, P., Apprendre à lire saint Paul, Desclée de Brouwer, 1981.

Legasse S., Lettres aux Philippiens et à Phm., CE, 33.

Le Monde de la Bible (revista) Nos. 5, 6, 12: Viajes de Pablo, núm. 137: ¿Qui a écrit la Bible?

Metzer, H., Les routes de saint Paul dans l'Orient grec, Neuchatel-Paris, 1954.

Quesnel, M., Les épîtres aux Corinthiens, CE, 22.

Saint Paul, Épître aux romains, Flammarion. 1973.

Tresmontant, C., Saint Paul, Éditions du Seuil, 1976.

\section{Per complementar}

Dictionnaire encyclopédique de la Bible, Brepols, 1987.

La Bíblia i el Mediterrani (2 volums), Publicacions de l'Abadia de Montserrat, 1997.

Lectio Divina, 165: Paul de Tarse, Éditions du Cerf, 1996.

Léon-Dufour, X., Dictionnaire du Nouveau Testament, Éditions du Seuil, 1996. 
Gairebé vaig aplegar tots aquests llibres, encara que no els vaig llegir tots, entre altres coses perquè n'hi havia que només eren de consulta i altres simplement els vaig fullejar. En vaig tenir prou. No sóc especialista de Pau de Tars, però reconec que com altres pensadors ell $\mathrm{m}$ 'ha torbat i no $\mathrm{m}$ 'ha permès viure com si res.

Llegint amb molta cura i no sense dificultat Sein und Zeit de Heidegger en versió original - Tübingen, Niemeyer 1976- em va cridar molt l'atenció l'ús del concepte Dichtung — «poesia», «ficció», «invenció», «fantasia»-. El verb dichten ha volgut dir: «inventar», «imaginar», "crear» com tanmateix ha significat, igualment, "condensació d'allò real». ¿Podia entendre la paraula paulina moria — ¿ «bogeria?»- com s'entén la Dichtung alemanya?. ¡l no són pocs els irreflexius que es fien càndidament de les traduccions, bisbes inclosos!

Tan frontalment vaig topar amb el text alemany de Heidegger, atesa la meva falta de coneixement de l'idioma, que vaig decidir valer-me de manera paral.lela de la versió francesa de Vezin —Gallimard, 1986-. Diu així:

La communication des possibilités existentiales de la disponibilité de l'existence, c'est-à-dire la découverte de l'existence, peut-être la fin que se fixe la parole qui «parle en poème».

Parle en poème tradueix la dichtenden de l'alemany heideggerià. Em semblava que descobria una forma captivadora de la moria grega de Pau. En Les Hymnes de Hölderlin -Gallimard, 1988- Heidegger torna al concepte del terme dichten:

«Dichten»... en rapport avec la «dictare» latin, qui est une forme fréquentative de «dicere».

«Dictare»,...exposer quelque chose par la langue... Montrer, rendre quelque chose visible, manifeste.

¿I si els textos paulins fossin no només disbarat segons l'Órganon d'Aristòtil, segons la Stoikheia d'Euclides i segons el Tractat sobre el mètode en teoremes mecànics d'Arquímedes, sinó que configuressin un discurs existencial en què la parole qui parle en poème no fes més que rendre quelque chose visible, sent tal cosa la découverte de l'existence; és a dir, el seu sentit i significat?

Curiosament va ser un marxista català, Manolo Sacristán, que un dia es va referir amb elogis al llibret De ente et essentia del dominic Tomàs d'Aquino (1218-1274). Havia redactat aquest opuscle quan era Professor universitari a París; succeïa entre 1254 i 1256. La millor manera de traduir el títol, De ente et essentia, podria ser: Sobre allò que existeix i sobre l'essència o, potser, de manera més salvatge: $A$ l'entorn de la vida i del pensament. Entengui's vida com el fet de viure-la. També pensament apunta a conceptes, o definicions, estàtics, immòbils, immutables. Per tant, moviment de l' «estar existint» obrint-se pas, davant de la segura quietud i el tranquil assossec del concepte acabat, decisiu i terminant. L'home de carn i ossos, singular, irrepetible, s'oposa al concepte d'humanitat, concepte que val per a tots els éssers humans i val sempre prescindint de tot canvi. Em vaig comprar el Ilibret, editat per Librairie philosophique J. Vrin, 1991, a París.

En el capítol III de l'opuscle de Tomàs d'Aquino hi llegim:

\footnotetext{
Patet quod essentiam hominis significat hoc nomen «homo» et hoc nomen «humanitas», sed diversimode...

Praedicatur hoc nomen «homo» de individuis...
}

Sed hoc nomen «humanitas»... non continet in significatione sua nisi id quod est hominis in quantum est homo. 
Dicimus quod essentia Socratis non est Socrates.

M'imagino que més d'un que hagi tingut la valentia de llegir aquestes pàgines, que es troben en ple off-side en aquests paratges i durant aquests temps de Facebook, n'agrairà la traducció:

\footnotetext{
Queda clar que els mots «home» i «humanitat» apunten a l'essència d'home; ara bé, ho duen a terme de manera distinta...

El terme «Home» es refereix a cada individu, al de carn i ossos. En canvi, la paraula «humanitat»... conté tan sols en el seu significat allò que és I'home en general en tant que ésser humà.
}

L'essència del Pere o de la Montserrat no coincideix amb l'individu concret; és a dir el Pere o la Montserrat als quals saludo.

El discurs de Pau de Tars cal intel-ligir-lo com una existència singular que intenta autocomprendre's alhora que proposa a altres el seu sentit de l'existència. En aquest línia va escriure a la Primera Carta als Corintis (capítol 15-verset 10):

Gràcies a Déu sóc el que sóc —«eimi o eimi»—.

Està en joc la seva existència singular, la qual dóna aquest salt vital —vida biogràfica; no vida biològica - mentre feia el camí cap a Damasc. De fariseu estricte salta a home lliure gràcies a l'esdeveniment salvífic Khristos - mort i resurrecció de Yeshua-; no s'argumenta la resurrecció de Crist, es viu; res més. El concepte logos queda fora de lloc. Antifilosofia. Pathós, això sí.

Només d'aquesta manera em fou possible abordar respectuosament Pau. Succeeix, a més, que la seva conversió gratuïta —ni Pere ni tampoc Jaume, el germà de Jesús, no el convertiren- pot ser presentada a altres, ja que si ell, Pau, es descobreix salvat per I'Esdeveniment -Jesús mort i ressuscitat-, també altres en poden ser partícips. Aquest no és un fet falsable; no és més que un canvi de frontera entre el possible i l'impossible. El logos no serveix per a aquesta tasca; a la Primera Carta als corintis:

Si algú creu saber — «egnokenai ti»— senyal és que ignora encara com ha de conèixer $(8,2)$.

¿No ens trobem, en paraules de Heidegger, amb la parole qui parle en poème, que se cenyeix a: rendre quelque chose visible, manifeste, més enllà del discurs argumentatiu?

Havia trobat la perspectiva idònia per capir Pau. No la línia de les essències, sinó el pla de l'existir circumstanciat; només així Pau resulta mostrable, abordable. Cada discurs tecnocientífic suprimeix el text paulí perquè Pau de Tars no fa més que donar testimoni de la seva convicció en la resurrecció de Crist, la qual no és un fet verificable, sinó un esdeveniment viscut de manera existencial.

El corpus dels escrits paulins indiscutibles queda reduït a: Romans, Corintis I i II, Gàlates, Filipencs, Tessalonicencs I. No ha faltat qui amplia el nombre d'epístoles fins a sumarne catorze. Em vaig inclinar pel que era irrefutablement segur; a més, això em bastava.

Ben aviat m'interesso per quina havia estat la primera col-lecció de cartes paulines a fi de conèixer quan havien començat a circular entre les diverses esglésies cristianes. Això me les feia respectables. Doncs bé; Marció va escriure, vers l'any 140, Apòstolos i en aquest text ja fa referència a una col-lecció d'epístoles de Pau; però abans Climent I de Roma, el quart Papa, bisbe de Roma entre l'any 89 i el 97, va escriure una carta als cristians de Corint en la qual fa referència als escrits de Pau, tot citant-los. 
La carta de Pau més antiga és la que va enviar a l'ekklesía de Tessalònica -Thessaloniké en grec - actualment Salònica, població de la Macedònia al nord de Grècia. Aquesta epístola està datada a l'any 50 o a inicis del 51. És el primer text del denominat, pels cristians, «Nou Testament». La carta la van enviar: Pau, Silvà o Silas i Timoteu — fundadors d'aquella comunitat-.

Pau escriu cartes perquè és la manera de fer-se present en els grups evangelitzats per ell i que es troben en alguna mena de conflicte. I no sempre es tracta de temes dogmàtics o bé morals; a vegades explota perquè algun predicador projueu, amb recomanació de Jerusalem, I'ha desqualificat com a apòstol, acusant-lo d'estafador, que l'únic que busca són diners. Em vaig quedar astorat llegint els capítols que van del 10 al 13 de la Segona Carta als corintis; heus-ne aquí uns retalls:

Jo, Pau en persona...

Em sento segur i quan vingui a vosaltres penso enardir-me amb aquells que em titllen de procedir segons les baixes passions...

Jo vaig ser el primer d'arribar a Corint amb la bona nova de Crist...

Aguanteu una estona la meva fúria una mica embogida: estic zelós de vosaltres com Déu és zelós...

Si el primer que es presenta proclama un altre Jesús diferent del que jo he predicat..., us ho empasseu tan tranquils...

Jo no sóc inferior a aquests superapòstols...

¿Per ventura vaig fer malament d'abaixar-me per enlairar-vos a vosaltres? al cap i a la fi no vaig fer més que anunciar-vos gratuïtament la bona nova de Déu...

Si Satanàs es disfressa de missatger de la llum, no ens ha d'estranyar que els missatgers es disfressin de servidors de la justícia...

Suporteu amb gust els insensats, vosaltres que us considereu intel-ligents; sí, suporteu que us esclavitzin... Si algú us explota, us estafa, li ho aguanteu... ¡Quina vergonya ser, jo, tan dèbil!...

¿Què heu d'envejar a altres comunitats, excepte que jo no he estat mai una càrrega per a vosaltres? Perdoneu-me...

Per tercera vegada estic preparat per anar a Corint; tampoc ara seré una càrrega...

Quan torni no estaré per contemplacions...

I res més, germans; estigueu alegres, recobreu-vos, tingueu ànims...

Amb tots vosaltres, el favor del Senyor Jesús Crist, l'amor de Déu i la participació de l'Alè — «Pneumaœ— sant.

No m'havia imaginat que aquell home, al qual m'havien presentat indefectiblement com un sant beneitó, fos precisament tan home i tan robust. El descobreixo igualment humà a la Carta als Gàlates $(6,11)$ quan cap al final escriu:

¿Veieu aquestes lletres tan grans? les escric amb la meva pròpia mà.

Això em féu preguntar com escrivien les cartes en aquell segle I i dins de l'imperi romà. He trobat una resposta satisfactòria a la revista Le Monde de la Bible (número 137, setembre-octubre de 2001). Primer es redactava el text de manera resumida sobre unes tauletes encerades. Només després un secretari reescrivia el text amb grafia normal sobre papir o sobre pergamí. Com que sabem que les comunitats de Pau eren pobres, cal suposar que feien servir el papir. Si la carta era llarga, es redactaven un parell, o tres, de capítols i es deixava per a un altre moment, o per a un altre dia, la continuació. Això 
explicaria perquè a vegades les transicions dins de la mateixa argumentació resulten abruptes; per exemple, entre els capítols 12 i 13 de l'Epístola als Romans.

El papir era fràgil; això requeria que es copiessin sovint els textos amb el risc, que suposa, d'intercalacions per part del copista. Un fragment d'una còpia de l'any 200, més o menys, on es troba escrit, en grec, el principi de la Segona carta als Corintis $(2,4)$, és de papir i es guarda a Doblí, a la Chester Beatty Library.

Durant aquells anys en què $m$ 'havia pres a pit els escrits de Pau vaig decidir dues coses: disposar d'una estructura biogràfica seva i visitar els llocs que ell havia trepitjat. Em semblava que aquesta doble precaució il.luminaria les meves lectures d'estudiós, no de beat de sagristia. Paro atenció sobre la manera com jo treballava: amb molts intervals atesa la meva responsabilitat universitària que era la tasca primordial. I, a més, sempre anava enderiat en diversos pensadors a la vegada. Gangues de l'ofici i de les sol-licituds que patia a cada moment vital.

A l'època vaig confeccionar un esquema cronològic i també un mapa de la Mediterrània oriental que em van situar Pau en el temps i en l'espai. Quan redacto aquests records no he reproduït exactament aquells recursos per a fer-me càrrec del text paulí; els he retocat. Història i geografia fan intel-ligible un escrit; si es prescindeix d'aquestes coordenades, I'obra pot quedar desnaturalitzada i àdhuc desfigurada. Tendim per natural a entendre un fet o bé un text a partir de les nostres coordenades espaciotemporals i actuant d'aquesta faisó perdem, inexorablement, ja sigui el text o bé el fet. Porto aquest parell d'eines tal com ara les he precisat.

La cronologia no s'ha d'agafar de manera rígida, sinó aproximada. Una indicació tenim segura: la compareixença de Pau davant de Galió, Procònsul romà de Grècia, la qual cosa situa l'estada de Pau a Corint entre l'hivern del 49-50 i l'estiu del 51. Pel que fa a la Segona Epístola als corintis no és possible datar-la perquè tal com ens ha arribat és la juxtaposició de tres missives de Pau als «sants» de Corint; això explica que I'hagi col.locat entre parèntesi.

\section{Pau (Saul, hebreu; Saulos, grec; Paulus, llatí) de Tars}

(Les dates són aproximatives)

\begin{tabular}{|c|c|c|c|}
\hline Dates & Fets & Cartes & Emperadors \\
\hline 7 & $\begin{array}{l}\text { Naixement a Tars } \\
\text { (Cilícia) }\end{array}$ & & August (31 a.C-14 d.C) \\
\hline $23-26$ & $\begin{array}{l}\text { A Jerusalem. Estudia } \\
\text { amb Gamaliel Ha-Zaken; } \\
\text { Gran Rabí. Es fa de la } \\
\text { secta dels fariseus. }\end{array}$ & & \multirow{6}{*}{ Tiberi (14-37) } \\
\hline 30 & Crucifixió de Jesús. & & \\
\hline 31 & $\begin{array}{l}\text { Martiri d'Esteve. Pau } \\
\text { persegueix els cristians. }\end{array}$ & & \\
\hline 32 & $\begin{array}{l}\text { Camí de Damasc. L' } \\
\text { «Esdeveniment»: } \\
\text { metanoia de Pau. }\end{array}$ & & \\
\hline $32-34$ & Damasc, Aràbia, Damasc & & \\
\hline 35 & $\begin{array}{l}\text { Conversa amb Pere i } \\
\text { Jaume, germà de Jesús, } \\
\text { a Jerusalem. }\end{array}$ & & \\
\hline $35-42$ & A Cilícia i Tars. & & Calígula (37-41) \\
\hline
\end{tabular}




\begin{tabular}{|c|c|c|c|}
\hline $43-46$ & $\begin{array}{l}\text { A Antioquia amb } \\
\text { Bernabé. }\end{array}$ & & \multirow{5}{*}{ Claudi (41-54) } \\
\hline $46-49$ & $\begin{array}{l}\text { Primer viatge: Xipre, } \\
\text { Anatòlia, Ikonion } \\
\text { (Konya). }\end{array}$ & & \\
\hline 49 & $\begin{array}{l}\text { Reunió amb Jaume, } \\
\text { Pere i Joan a Jerusalem } \\
\text { (Concili?). }\end{array}$ & & \\
\hline 49 & $\begin{array}{l}\text { Segon viatge: Tessalòni- } \\
\text { ca (Salònica), Macedò- } \\
\text { nia. }\end{array}$ & & \\
\hline $50-51$ & A Corint & I Epístola a Tessalònica & \\
\hline $53-56$ & Tercer viatge: A Efes & $\begin{array}{l}\text { Epístola als gàlates } \\
\text { I Epístola als corintis } \\
\text { Epístola als filipencs }\end{array}$ & \multirow{6}{*}{ Neró (54-68) } \\
\hline 57 & Macedònia & (II Epístola als corintis) & \\
\hline $57-58$ & A Corint & Epístola als romans & \\
\hline 59 & $\begin{array}{l}\text { Jerusalem: hi porta la } \\
\text { col·lecta havent passat } \\
\text { per Macedònia, Tròade, } \\
\text { Milet. }\end{array}$ & & \\
\hline $59-60$ & $\begin{array}{l}\text { Arrestat a Jerusalem. } \\
\text { Traslladat a Cesarea } \\
\text { Marítima; Procuradors } \\
\text { romans: Fèlix i Festus. }\end{array}$ & & \\
\hline 60 & $\begin{array}{l}\text { Cap a Roma, presoner: } \\
\text { Naufragi: Malta i, per fi, } \\
\text { Roma. }\end{array}$ & & \\
\hline 68 & $\begin{array}{l}\text { Mort martirial a Roma } \\
\text { segons el papa Climent, } \\
\text { Papa entre } 89 \text { i } 97 .\end{array}$ & & Galba (68-69) \\
\hline
\end{tabular}

\section{Sant Pau}

Figura 1. Ciutats i zones significatives

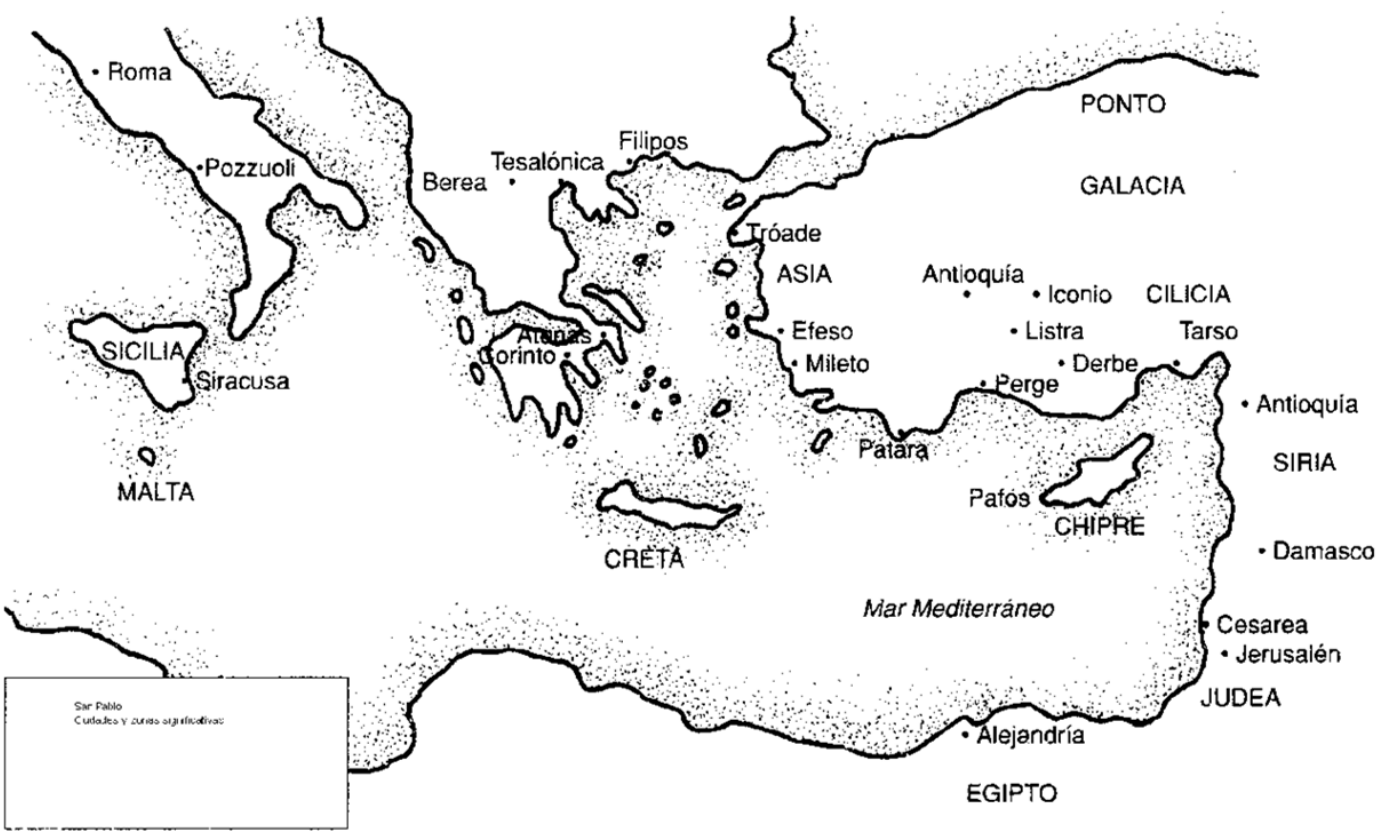

Vaig fer el possible per recórrer els espais paulins i conèixer sobretot Tars, però això últim fou en va. M'ha dolgut sempre més. Tars, actualment població de l'Estat turc, es 
troba tocant al riu Cydnos i molt a prop del mar. En temps de sant Pau era capital de la província romana de Cilícia, amb uns 300.000 habitants, i tenia una important comunitat jueva. Pau després de la seva transcendental metanoia - «canvi radical de mentalitat»- hi va residir durant uns anys, segons consta a Gàlates $(1,21)$, després d'haver-se entrevistat a Jerusalem amb Pere i amb Jaume, el germà de Jesús. En grec, meta significava «canvi», «d'una banda a l'altra», «transformació»; i nóos era «intel.ligència», «ment», «pensament», «esperit». Metanoia.

A la Tars de Pau, gaudia de prestigi una escola filosòfica de caire estoic. No m'estranyaria que hi anés alguna vegada malgrat ser jueu. Els jueus de la diàspora es van deixar inculturar per l'hel.lenisme i fins i tot alguns assistien al gimnàs —on es formaven cos i esperit- i a espectacles públics com el teatre. L'estoïcisme del segle I propugnà el monoteisme filosòfic amb el qual podia sentir simpatia un monoteisme bíblic. Vaig tenir present també Filó d'Alexandria (20 aC-50 dC), contemporani de Pau, un jueu que representà de forma eminent el judeohel-lenisme.

Imagino el meu Pau de Tars abans d'anar a Jerusalem i estudiar la Torah amb el gran mestre Gamaliel. Me l'imagino amb dos punts de referència existencials: el país on viu i la terra dels seus avantpassats. Ell és un jueu de la diàspora - mot grec que significa «dispersió»; aquesta dispersió s'havia iniciat amb la deportació jueva que féu Nabucodonosor II al segle vı a.C.- - En temps de Pau hi havia més jueus fora de Palestina —uns quatre milions - que a la mateixa Palestina —uns dos milions-.

Sens dubte Pau, un cop apartat del judaisme oficial, ha esdevingut el primer gran pensador del cristianisme. La seva concepció del fet cristià no es va forjar a partir de la predicació de Jesús —ell és un cas a part, un subjecte de la diàspora, coneixedor de I'hel-lenisme-, sinó que va descobrir el sentit cristià en la mort de Jesús i en la revelació de la seva resurrecció. El fet d'arrencar de Tars, el convertí en diferent, distint; Santiago, Pere, Joan..., en canvi, era gent de la Palestina que havien tractat Jesús, un jueu rebel, però jueu.

En diversos estius i en diferents anys, vaig anar coneixent els espais arqueològics de les ciutats paulines; no es pot perdre de vista que Pau propagà la seva fe en Crist en un món urbà, no com Jesús que va predicar en espais rurals. No li importaven a Pau els possibles miracles de Jesús ni els seus sermons, ni tampoc les seves dades biogràfiques. Únicament dos moments: mort i resurrecció. Va prescindir de tota la resta. I encara mort i resurrecció en tant que vivències personals i no pel que fa a fets històrics, verificables.

La major part de geografies paulines les vaig visitar amb Professors d'Història de la Universitat de Barcelona; ens guiava el Doctor Salvador Claramunt. Aquest fou el cas de Jerusalem, Antioquia tocant al riu Orontes, Ikonion, Tessalònica o Salònica, Milet, Damasc, Cesarea Marítima i Troas o Tròade. Amb la meva germana Maria vaig recórrer: Corint, Atenes, Efes i Roma. Recentment he afegit a aquesta llista acompanyat de I'Antònia Borràs: Malta i Xipre. Algunes d'aquestes poblacions les he visitat en més d'una ocasió; és el cas d'Atenes, Roma, Efes i Corint. Invariablement no només he posat interès a les restes arqueològiques carregades de memòria històrica, sinó que també he escrutat els paisatges que Pau va contemplar, així com m'he deturat en més d'un moment fitant el cel en diferents instants del dia i de la nit, amb la intenció d'atrapar algunes emocions recòndites de Pau. 
El viatge a Ikonium —-lkonion en el grec paulí; Konya, a la Turquia actual- el férem en autocar sortint de Miletos - Milet - per on desemboca el llarg riu —584 kilòmetres- Büyük Menderes - Meandros a l'època grega-. Visitàrem la romana Aphrodisias i franquejàrem ports de muntanya considerables i llacs de gran extensió. Aydin, Denizil, Isparta...; vaig arribar a Konya, esllomat. Ni els balls místics dels actuals derviches -que provenen del segle XIII-, veritables baldufes giratòries humanes, em van alliberar de la fatiga. Al vespre no em podia treure del cap com Pau de Tars, que hi predicà acompanyat de Bernabé (Fets, 13, 51), va poder resistir semblants trots. I ell anava a peu.

Ja he referit abans les meves estades a Atenes, Corint i Efes. No hi torno. Un record peculiar em ve ara a la memòria: la visita a la ciutat de Salònica - Thesaloniké, en el grec de Pau, dins de la província romana de Macedònia, on acabava la via Egnatia, procedent del Mar Adriàtic - Pau va estar a la ciutat acompanyat de Silas a fi de portar el seu missatge revolucionari a la comunitat jueva. Probablement hi va anar en dues ocasions, el 49, o el 50, i el 56, convertint a la seva rebel-lia antijueva, jueus i també grecs. Hi devia residir uns tres mesos en la primera visita. En el transcurs del viatge em va fer caure d'esquena l'Arheologiko Moussío —-Museu arqueològic_, sobretot el Tresor de Vergina amb la tomba reial de Felip II de Macedònia, pare d'Alexandre el Gran.

A Damasc —Damaskos en grec - la principal població de Síria, em vaig adonar que la ciutat formava un punt estratègic notable; era l'encreuament de dues rutes importants de caravanes: la Via Maris — que unia la Mesopotàmia i Egipte- i la Via Regis que anava des del nord de Síria fins al Mar Roig. Els romans la van ocupar l'any 64 a.C. passant així a formar part de Síria; la comunitat jueva fou abundant. Els cristians de la ciutat eren probablement essenis convertits. Em vaig passejar pel decumanus, via a la qual es refereix sant Jeroni a la Vulgata relacionant Ananies amb Pau:

Surge, et vade in vicum qui vocatur «Rectus»...Vade, quoniam vas electionis est mihi iste, ut portet nomen meum coram gentibus (Actus Apostolorum; 9, 11-13).

De Damasc, Pau s'escapà de forma rocambolesca segons narra ell mateix a la Segona Carta als Corintis:

A Damasc el governador del rei Aretes tenia muntada una guàrdia a la ciutat per tal de fer-me agafar; posat en una sàrria em van despenjar per una finestra de la muralla i així vaig escapar-me de les seves mans $(1,32-33)$.

Em van ensenyar el lloc exacte d'una fugida tan estrafolària, però vés a saber. Han transcorregut massa segles.

Com a mínim hi ha dues Antioquies: Antioquia de Pisídia al centre de l'Àsia Menor - Turquia actual - , on Pau hi va estar en tres ocasions, i Antioquia tocant al riu Orontes, riu que neix al Líban; en aquesta segona ciutat Pau hi residí un temps. Només he visitat I'Antioquia del riu Orontes. Havent apedregat Esteve a Jerusalem, alguns cristians es refugiaren en aquesta Antioquia on per primera vegada van rebre el nom de cristians. El responsable d'aquesta ekklesía era Bernabé, el qual va ajudar Pau de Tars durant un any. D’allí partiren, ambdós, per evangelitzar Xipre i l'Àsia Menor tornant a Antioquia després de cada viatge.

La ciutat fou conquerida pels romans l'any $64 \mathrm{aC}$; fou un centre comercial d'envergadura situat a 22 kilòmetres del mar i cruilla de les caravanes que procedien de l'Àsia Menor i de la Mesopotàmia. Va ser un gran focus hel.lenístic, després de Roma i Alexandria. Tenia uns 400.000 habitants, el deu per cent dels quals era jueu. 
El rebel Pau va tenir un conflicte seriós amb Pere en aquesta Antioquia; ell mateix ho narra en la carta que envià als gàlates, als quals havia evangelitzat l'any 50, i que visità després l'any 53. La carta molt probablement la va escriure a Efes, I'any 56, en assabentar-se que uns judeo-cristians volien imposar la circumcisió als seus convertits que venien del paganisme. Diu el text amb un inici dur:

Pau, enviat no per homes ni per intervenció humana, sinó per voluntat de Jesús, el Messies... $(1,1)$.

Ben aviat em vaig adonar del to tan neguitós. Ell no parlava en nom de Jaume, el germà de Jesús, ni tampoc de Pere, ni del grup de Jerusalem. Ell era independent ja que Jesús I'havia escollit de manera directa. Aquesta era la seva convicció després que l'Esdeveniment — «Mort-Resurrecció de Crist»— s'apoderés d'ell alliberant-lo de l'esclavitud de la Llei, de la Torah.

Prossegueix, la carta, més endavant:

\begin{abstract}
Quan «Cephas» —Pere— va anar a Antioquia, m'hi vaig haver d'acarar i resistir perquè s'havia condemnat amb la seva conducta. Va ocórrer que: abans que arribessin certs individus del grup de Jaume, el germà de Jesús, Pere menjava amb els pagans, però heus aquí que un cop aquests van arribar se n’apartava tement els partidaris de la circumcisió.
\end{abstract}

Els altres jueus es van associar a la seva comèdia; fins i tot Bernabé es deixà arrossegar per aquella farsa.
En veure que no procedien correctament i que abandonaven la veritat de l' «Anunci», li ho vaig retreure a
«Cephas» davant de tots:

-Si tu, sent jueu, vius com un pagà i no com un jueu, ¿com vols ara forçar els pagans a comportar-se com a jueus?...

Nosaltres érem jueus de naixement... però hem comprès que cap ésser humà queda justificat pels seus actes conforme a la Llei, sinó per la fidelitat a Jesús, el Messies. Per això nosaltres hem cregut en Jesús, el Messies... Pels actes conforme a la Llei, cap carn quedarà justificada. $(2,11-16)$

Llenguatge tallant i viu, aquest de Pau. Antioquia quedà vinculada a la rectitud i a la naturalitat del meu personatge, el qual no estava per tapabruts ni tampoc per enganyifes.

Tròade - Troias en grec - fou una ciutat fundada per Alexandre el Gran al sud de Troia, a prop dels Dardanels entre el mar Egeu i el Mar de Màrmara. Pau hi va estar tres vegades. Diu a la II Carta als corintis:

Vaig arribar a Tròade per anunciar la «Nova» del Messies, però, tot i que se'm presentà l'ocasió, en no trobar allí Titus el meu company en la predicació, no em vaig quedar tranquil; em vaig acomiadar d'ells i vaig sortir cap a Macedònia.

Els dies de la meva estada a Israel em permeteren conèixer dos llocs paulins: Jerusalem i Cesarea Marítima. Yerushalayim en hebreu significà «Ciutat de pau» — d'uru, «ciutat», i de shalem, «pau»-. En grec era Hierosolyma. El rei David 1010-970 aC. la va conquerir als jebuseus. Centre del poble hebreu. El temple de Salomó quedà destruït el 586 aC.; el segon temple el van abatre els romans l'any 70. Pau havia mort ja a Roma. La ciutat de Jerusalem ocupa un altiplà a 700 metres sobre el nivell del Mediterrani.

A Jerusalem, s'hi fundà la primera comunitat de creients en Crist sota la presidència de Jaume que era germà carnal de Jesús.

Jerusalem la van trepitjar per primera vegada els soldats de Roma l'any 63 aC. Pau hi va anar, l'any 49 i el 59 dC., moment en què quedà presoner dels romans. Fou llavors que aquests el van enviar a Cesarea Marítima. En grec, Cesarea era Kaisareia. Diverses poblacions duien aquest nom en honor a Octavi August; la que m'interessà fou la Cesa- 
rea Marítima o Cesarea de Palestina, fundada per Herodes el Gran (73-4 aC.) damunt d'una ciutat grega. A partir de l'any 6 va ser residència dels Procuradors romans a Palestina. Aquí van enviar Pau des de Jerusalem. Festus, el procurador, el lliurà als tribunals de Roma. Fets dels apòstols en fa una descripció una mica novel-lada. N'extrec un fragment.

-Pau va respondre:

...Apel.lo al Cèsar.

Festus respongué:

—Has apel·lat al Cèsar, doncs al Cèsar aniràs. (25, 11-12)

El viatge a Roma té lloc a la tardor del 59, època de tempestes al Mediterrani. Naufraguen a prop de l'illa de Malta i allí es refugien. Vaig visitar l'illa amb l'Antonieta Borràs. La meva mirada topà amb els mateixos paisatges que havia vist Pau. Això em va plaure. A la primavera del 60 el vaixell pogué assolir finalment Roma. Un cop arribats a la capital de I'Imperi, Pau va haver d'esperar per ser jutjat. Va morir finalment decapitat, segons el Papa Climent, que era bisbe de Roma entre el 89 i el 97. Pau havia mort a l'any 67 o al 68. La informació sembla fiable.

Totes les vegades que he passejat pels Fòrums Imperials de Roma, he estat atent al Forum Augusti, de l'emperador Octavi August com també al de Juli Cèsar; sense dubte que Pau els va veure i s'hi va passejar. M'ha semblat crucial entrar en les interioritats del personatge estudiat per tal de conèixer-lo millor.

Va arribar el moment en què em trobava prou preparat per llegir, d'una vegada, els escrits de Pau. Em vaig limitar a les cartes indiscutiblement paulines. Ho vaig fer segons l'ordre cronològic en què van ser redactades, en la mesura que aquesta qüestió es pot precisar. D'altra banda, alguna de les cartes tal i com ens han arribat inclou més d'una missiva. Finalment vaig decidir, durant unes vacances de Setmana Santa, la llista de les meves lectures. Fou la següent.

1-Primera carta als «sants» de Tessalònica (de l'any 50 o 51).

2-Primera carta als corintis (cap a l'any 51).

3-Carta als gàlates (vers l'any 55).

4-Carta als «sants» de «Philippoi» (als filipencs) (entre el 55 i 57).

5-Segona carta als corintis (juxtaposició de diversos escrits) (datació difícil).

6-Carta als romans (cap al 55).

Thessaloniké, actualment Salònica, era la capital de la província de Macedònia durant l'època romana imperial, quan hi arribà Pau de Tars. Hi fundà una ekklesía - comunitat o assemblea- de creients en la resurrecció de Crist, grup de creients format per jueus i, sobretot, per grecs. La missiva que els envia Pau constitueix el primer document cristià que tenim. Pau, de fet, posà les bases intel.lectuals del que esdevindria el cristianisme.

Amb la denominació de gàlates es refereix, a la carta, a petites comunitats de creients de l'Àsia Menor, d'Ikonion —Konya actual— per exemple. He referit abans la resta de poblacions a les quals Pau va enviar cartes. 
Tot seguit em vaig preguntar quin era el nucli dur del pensament paulí. No em volia perdre en temes secundaris. Em va cridar l'atenció, això sí, que les seves idees no vinguessin de la predicació de Jesús. No en fa ni una sola referència. Tampoc no va ser convertit per part dels familiars de Jesús ni per aquells que l'havien tractat directament. ¿Com se'l pot comprendre?

Durant la meitat de la seva vida, Pau fou un jueu de la secta dels fariseus. Els pharisaioi - terme grec - practicaven amb rigor la disciplina moral de la Torah — La Llei-, fet que els colllocava a part de la resta de la població. Observaven exactament el que estava prescrit. Per això havien elaborat 613 regles de conducta, de les quals 248 eren preceptes i 365 constituïen prohibicions. La pràctica sincera de La Llei els duia a la salvació. El nom hebreu de Pau era Saül.

Com a bon jueu devia estar casat; per què? un rabí esperava el Messies que naixeria d'una dona.

En tant que fariseu, ¿com va entendre Jesús? Per a ell, Jesús era, aleshores, un transgressor de La Llei que Déu havia donat al poble jueu. Menjava amb els cobradors d'impostos romans i amb els pecadors, i va ensenyar els seus seguidors a comportar-se així. Jesús fou un blasfem i com a tal rebé el càstig de la crucifixió; al cap i a la fi el Deuteronomi determinà:

Si un sentenciat a pena capital és ajusticiat i penjat a un arbre...

Déu maleeix el qui penja d'una creu. $(21,22-23)$

Quan Pau torna a Jerusalem, als anys 30, descobreix amb la sang que se li gela a les venes que Pere, Jaume, el germà de Jesús, i altres que havien estat amb ell asseguraven públicament que el blasfem impostor, segons Pau en aquells dies, era el Masiah, el Messies tan anhelat pel poble jueu. Com a bon teòleg, Pau s'adona a l'instant que aquell moviment naixent pot fer que la doctrina rebuda dels avantpassats trontolli. Fariseu intransigent, quan es tracta de la puresa de la fe, decideix combatre la secta iniciada i marxa a Damasc per a perseguir els deixebles d'Esteve que s'havien refugiat en aquella ciutat.

Però, heus aquí que aleshores succeeix, en la vida de Pau, l'Esdeveniment, la seva metanoia, la transformació total de la seva manera de pensar i de sentir. El retir d'un parell d'anys al desert d'Aràbia, com també la seva llarga estada d'uns sis anys a Tars, la població natal, el referma en la seva decisió. Per a mi, aquesta alteració biogràfica radical constitueix una zona molt difícil de capir. El que és indiscutible, no obstant, és aquesta cesura brusca que divideix en dues meitats la biografia paulina. La segona meitat no és conseqüència d'una dialèctica o d'un raonament, sinó un cop terrible en la seva existència personal. Ho consigna a la Primera carta als corintis:

Per gràcia de Déu, sóc el que sóc —«eimi o eimi»—. $(15,10)$

És com dir: sóc creient per fulminació i no per cap raó o bé per causa de la predicació convincent d'algú. Alguna cosa va saltar brutalment del seu inconscient a l'àmbit de la consciència. Les conseqüències intel-lectuals foren considerables; escriu a l'Epístola als Gàlates:

¿Que potser tracto, ara, de regraciar-me amb els homes o amb Déu? ¿direu que busco de plaure als homes?. Si encara intentés d'acontentar els homes, ja no podria estar al servei de Crist. $(1,10)$ 
El tall que separa el Primer Pau del Segon és terrible com ell mateix confessa a la Carta als Filipencs:

Tot això que per a mi era guany, ho vaig considerar pèrdua comparat amb el Crist; encara més: qualsevol cosa em sembla perduda al costat de la grandesa que és haver conegut personalment el Crist Senyor Jesús. Per ell ho he perdut tot... Que pugui ser jo reconegut a través seu i no per la meva pròpia justícia, aquella que dóna la Llei. $(3,7-9)$

A partir de l'Esdeveniment, el crucificat deixa de ser un blasfem, que rebé el seu càstig, per passar a ser el fill de Déu. A la carta als Gàlates va escriure:

\footnotetext{
Quan Déu ho jutjà prudent -Aquell que em va escollir des del si de la meva mare i em va cridar per la seva gràcia- es dignà revelar-me el seu Fill perquè l'anunciés a les nacions. No vaig consultar a ningú de carn i ossos, ni tampoc vaig pujar a Jerusalem per veure els apòstols anteriors a mi, sinó que immediatament vaig sortir cap a Aràbia, d'on vaig tornar altra vegada a Damasc.

Després, tres anys més tard, vaig pujar a Jerusalem per conèixer Cephas —Pere- i em vaig quedar quinze dies amb ell. No vaig veure cap altre apòstol, excepte Jaume — Santiago—, el germà del Senyor. (1, 1520)
}

Déu li rebel-là directament que Crist és el seu fill; és a dir, que és fill de Déu. No s'ha de prendre al peu de la lletra; es tracta d'una fórmula bíblica per assenyalar que es tracta d'algú molt preuat per Jahvé. El Crucificat ha deixat de ser un blasfem i es converteix ara en el Salvador diví. Aquest text, a més, subratlla que això Pau no ho sap perquè li ho hagin ensenyat els apòstols anteriors a ell, sinó que el mateix Senyor li ho ha comunicat; és a dir, fou quelcom que va viure tot sol.

Com he indicat abans, no podia sortir del meu estupor, no encertava a explicar-me les dues biografies de Pau: ¿com passà de perseguidor d'aquells jueus, que consideraven que Jesús era el Messies esperat, a fervent proclamador de Jesús, el Crist?. Allò de la caiguda del cavall és literatura simbòlica, però de cap manera no és un fet històric clavat en l'espai i en el temps. Vaig llegir, ben cert, Fets (9,1-19), però, és clar, no vaig encertar a veure en el text novel.lat cap altra cosa que el simbolisme sobtat del canvi radical, que havia sofert Pau a la seva biografia. Hi ha hagut un Marx jove i un Marx madur; Louis Althusser (1918-1990) n' ha donat una explicació a Pour Marx (1965). Hem tingut també el Primer Freud i el Segon Freud, el Freud de La interpretació dels somnis (1900) i el Freud de Més enllà del principi de plaer (1920), però en aquest cas el mateix autor constata el canvi introduït en la seva producció.

Em vaig afanyar i fatigar per poder entendre el salt existencial fulminant que sofreix Pau a la seva vida biogràfica. Confesso que vaig suportar turment fins que en una matinada d'insomni, i, estant encara al Ilit, em vaig adonar que l'antropologia del Primer Freud em podria auxiliar. Buscava un model epistèmic per tal d'intel-ligir la brusca metanoia soferta per Pau quan devia tenir uns 25 anys.

¿Què passava en l'inconscient —Das Unbewusste- d'aquell fariseu zelós del compliment sever de la Torah?. Em refereixo a Inconscient en el seu significat tòpic, el qual està format pels continguts reprimits que no han pogut aflorar en el sistema «preconscient-conscient» per la repressió exercida a fi d'evitar el dolor del pecat. El pecat de no complir estrictament La Llei-Torah-.

Pau de Tars en el seu inconscient desitjava amb fervor la felicitat, el goig, però tal desig quedava reprimit, i per tant desconegut, en el seu sistema inconscient. Hauria estat pitjor haver de carregar conscientment amb la falta de no complir La Llei, ell, preci- 
sament, un fariseu fervorós. La libido, entesa com a desig de felicitat, romania amagada, tot i que no pas suprimida. Pau era desventurat, a causa de La Llei llegida com a fariseu.

Devia tenir 23 o 24 anys quan va assistir a la lapidació mortal d'Esteve, un d'aquells jueus que estaven convençuts que el crucificat Jesús era el Mashiyah tan esperat. El relat que en fan els Fets dels apòstols, un llibre novel.lat que s'ha proposat mostrar la construcció de la identitat cristiana com a institució social distinta de la jueva, és un llibre que fantasieja sobre fets, que, no obstant, han succeït. El relat sobre Esteve va des del capítol 6 , verset 8 , fins al capítol 8 , verset 3 . En porto un fragment, més sobri per cert, que ve al cas:

Esteve... va dir:

—Veig el cel obert i el Fill de l'Home dret a la dreta de Déu.

Fent, tots, un gran crit i tapant-se les orelles, es van abalançar a sobre d'ell; el van empènyer a fora de la ciutat i el van apedregar. Els testimonis, que havien deixat les seves capes als peus d'un jove anomenat Saule, es van posar a apedregar Esteve, que repetia aquesta invocació:

—-Senyor Jesús, rep el meu esperit.

Després caient de genolls, Ilençà un crit:

-Senyor, no els tinguis en compte aquesta falta.

I amb aquestes paraules va expirar.

Saule aprovava l'execució.

Aquest fet devia sacsejar l'inconscient de Pau. La sang d'Esteve donava testimoni del Senyor Jesús; ara bé,

Saule s'acarnissava amb l' «ekklesía» — «convocació»— d'aquells homes. Penetrava a les cases i arrossegava a la presó homes i dones... (Fets, 8, 3)

Saule... va anar a veure el Sacerdot Suprem i li demanà cartes per a les sinagogues de Damasc que l'autoritzessin a detenir... tots els que seguien aquell camí. (Fets, 9, 1-2)

Tot seguit ve la narració, fantasiosa, de la caiguda del cavall. ¿Què va passar? explotà el seu inconscient insuportable. Renega de La Llei, la qual en la seva biografia s'havia convertit en turmentador sàdic. Jesús el salvava de la Torah. S'hi entrega. Crist li treu les cadenes de l'esclavatge i el converteix en home lliure i, per fi, feliç.

Segons Pau, Jesús és un ésser humà, tot i que Fill de Déu — «algú excel·lent»— que va venir per rescatar-nos de La Llei:

Quan va arribar la plenitud dels temps, Déu envià el seu fill, nascut d'una dona, arribat sota «La Llei» a fi de rescatar aquells que estaven sotmesos a «La Llei». (Gàlates, 4, 4-5)

La llei, la Torah, el torturava fent-lo dolent. El capítol 7 de la Carta als romans em resultà contundent, aclaparador, i em va fer intel.ligible la caiguda del cavall. La Llei el feia un desgraciat, un infeliç. Necessitava que Algú I'alliberés de La Llei i de les seves conseqüències inconscients:

Jo no coneixia el pecat a no ser per «La Llei»... No sabia el que era un mal desig fins que la llei va dir: «No tinguis mals desitjos»...

Quan no hi havia llei, tot era vida per a mi; però en venir el precepte, féu reviure la força del pecat i jo vaig quedar mort...

No faig el bé que vull, sinó el mal que avorreixo... ¡Pobre de mi! ¿Qui m’alliberarà d'aquest ésser meu, instrument de mort? 
En llegir aquesta pàgina paulina m'he vist forçat a evocar Les confessions (400) de Sant Agustí (354-430) per la seva frescor i la seva sinceritat.

A la Segona Carta als Corintis hi ha una sentència de Pau que resumeix la seva tragèdia interior de la qual l'allibera Crist:

To gramma apoktennei, to de pneuma zoopoiei. $(3,6)$

(«La lletra de la llei mata, mentre que l'Alè fa viure»).

Jesús, el de la història, es torna Khristos — messies, l'ungit - gràcies a la seva mort a la creu i la seva posterior resurrecció. A la Carta als filipencs:

Ell, tot i la seva condició divina, no s'aferrà a la categoria de Déu; al contrari, es va buidar del seu rang fent-se esclau i un de tants...

S'humilià fins a la mort i una mort de creu... Per això Déu l'encimbellà... I tota boca proclama que Jesús, el Crist, és Senyor per la glòria de Déu Pare. (2-11)

\section{I a la Primera carta als Corintis:}

Us he transmès allò que vaig rebre d'essencial: Crist va morir per les nostres culpes... fou sepultat i al tercer dia ressuscità... S'aparegué a Cephas i més tard als Dotze... Per últim se m’aparegué també a mi, un fetus avortat. $(15,3-9)$

La mort i resurrecció de Crist, no La Llei, és allò que salva.

La resurrecció, que converteix Jesús en Crist, el personatge històric en personatge de fe ¿va tenir lloc en la successió temporal? No. La resurrecció no és una veritat que els historiadors puguin comprovar; es tracta d'una veritat existencial i de cap manera verificable. La resurrecció de Crist és veritat en la mesura en què dóna sentit a l'existència de Pau i de tots aquells que, com Pau, en viuen. Ja no és La Llei, la Torah, tan turmentadora ella, la que ajuda a viure, sinó la crucifixió de Jesús i la resurrecció de Crist.

El Crist de la fe és Kharis, una gràcia, un pur do; no és de cap manera una dada científica. A la Carta als Romans:

El pecat no tindrà domini sobirà sobre vosaltres. Ja no esteu sotmesos a la influència de «La Llei», sinó de la gràcia — «haris», do-. $(6,14)$

Un detall em va despertar molt d'interès. Pau no buscava només felicitat quan apartava La Llei de la seva vida, sinó que defensava la felicitat universal, la de tothom, i no, per cert, la d'un sol poble, el jueu. A la Carta als Gàlates:

Tots els que heu estat submergits en el baptisme, us heu revestit del Crist. Ja no hi ha ni jueu, ni grec; ni esclau ni home lliure; ni home ni dona, ja que tots vosaltres sou una mateixa cosa en Crist Jesús. (3, 2628)

La Carta als Romans insisteix en la mateixa idea segons la qual la felicitat és per a tots els éssers humans:

Aflicció, angoixa, per a tota persona humana que obra malament, en primer lloc el jueu, però també el grec.

Esplendor, honor i pau per a tots aquells que practiquen el bé; en primer lloc el jueu, però també el grec.

Perquè Déu no té favoritisme. $(2,9-11)$

Un Déu universal és garantia de la felicitat de tothom. La joia no es reserva a una raça, a un gènere, a una classe social; cada ésser humà és cridat a ser feliç. 
Pau de Tars no va atrapar la meva vida intel.lectual perquè fos un sant cristià; va ser a pesar d'això. En ell vaig descobrir un home intel-ligent que vivint torturat per la pràctica rigorosa de La Llei, finalment se n'escapa i abraça la llibertat existencial. El personatge idealitzat Khristos fou el seu salvador. No he fet cap estudi crític de sant Pau; senzillament he procurat descobrir per què ingressà en la meva biografia de Professor universitari. Confesso, malgrat tot, que no vaig parlar de Pau als meus alumnes; em va semblar inoportú per una sensibilitat que aleshores confonia religió i franquisme — dictadura del general Franco-.

En educació el tema de la felicitat se $m$ 'ha presentat insubornablement com un tema majúscul. ¿Per què? perquè és una qüestió antropològico-filosòfica capital. Per aquesta raó el compliment dolorós de La Llei, com a bon fariseu que era Pau, em va interessar tot seguit. Aquest sofriment xocava de manera frontal amb el desig incorruptible de felicitat total. Ara bé; resultava inesquivable haver-ne d'afrontar la semàntica. ¿Què havia d'entendre amb el terme felicitat?.

Heus aquí una llista de significants que, d'antuvi, em van torturar amb els seus possibles significats: eutukhia, eudaimonía, makariotes — de l'àmbit grec-; felicitas, beatitudo -de l'esfera llatina_; Glückseligkeit, Glück, Seligkeit, Wohlfahrt —de l'univers germànic-; happiness, luck, Welfare — de la cultura anglesa-; bonheur, felicité, béatitude, chance —del món francès-; contento, felicidad — del desenvolupament lingüístic castellà-; joia, felicitat — de la cultura catalana—.

A l'Ètica a Nicòmac i a l'Ėtica a Eudem d'Aristòtil vaig descobrir precisions lèxiques significatives. Tanmateix a la Summa theologiae de Tomàs d'Aquino i a Malestar en la civilització de Freud, hi vaig trobar idees que venien al cas des de la perspectiva semàntica.

¿En quin significat de felicitat, Pau de Tars es llança als braços de Crist? Quan vaig abordar el per què de la joia en els processos educatius vaig acabar construint un univers semàntic que havia obtingut de lectures d'autors, principalment clàssics, i de l'estructura felicitant de l'ésser humà.

Vivim inexorablement en un hic - aquí- i en un nunc —ara-; és a dir, no podem esquivar ser sarx — «carn viva»- Moments hi ha en què se'ns dispara l'acte de consciència o apercepció del moment viscut. Es tracta d'una Erlebnis, vivència puntual. Tal experiència ens dispara la in-satis-facció, el dolor de no coincidir amb nosaltres mateixos. Ens dol tant la insatisfacció, o inacabament personal experimentat, que ens posem a esperar temps millors a base de projectes que planegem. Alguns d'aquests projectes arriben a bon terme i aleshores experimentem contentament, que és la eudaimonía dels grecs i la felicitas dels romans. Però, aviat l'acontentament es fon i desapareix i tornem a caure en la insatisfacció. Quelcom insuportable, i de nou a projectar. Inacabable feina o ocupació. Com la de Sísif.

Molts, entre ells sant Pau, ingressen llavors en l'Ad-ventura abrahàmica, en l'Eros platònic, en l'Amor Dei agustinià. En aquesta nova dimensió es pretén sortir de la quotidianitat, del que és experimentable, fent un salt cap al transcendent. En aquest supòsit es persegueix l'impossible, al meu parer: Yahvé, l'Agathon, l'Absolut o Déu. En cas d'assolirlo - cosa impracticable-, s'obté, el Makariotes, la Beatitudo, la Felicitat Plena, que és quelcom per sempre més, per a «fora-temps-i-espai». 
A Crist, Pau l'estima perdudament perquè l'ha salvat del turment que li causava la submissió inflexible, pròpia d'un fariseu, a La Llei. L'experiència d'aquesta emoció vers el Crist dóna eudaimonía, felicitas, content, situació que ve amargada per les successives i tossudes situacions de la biografia. Per això Pau es refereix a un fruir de Crist post mortem; és llavors, quan definitivament gaudirà de Makariotes, de Beatitudo, de Felicitat Plena, si tal gesta és possible, més enllà de l'antull.

Crec que vaig entendre la peripècia existencial de Pau. A més - i ho subratllo- va voler que el dret al Contentament i també a la Felicitat Plena fos per a tothom i no solament per a uns privilegiats. Em va caure bé Pau i continuo admirant-lo. A més, he descobert en ell un ésser humà sincer $\mathrm{i}$ íntegre, i també intel-ligent i culte, cosa no gens freqüent en els temps que corren per aquestes terres de la Pell de Brau. 


\section{Pablo de Tarso (10-67): me quedé patitieso}

Resumen: Este artículo presenta el perfil de Pablo de Tarso que el autor no conoció hasta que visitó Atenas en el año 1969. Fue entonces cuando, acompañado de su hermana María, se dio cuenta de la magnitud del mensaje paulino, que lo dejó patitieso. Sin duda, Pablo -una vez apartado del judaísmo oficial- se ha convertido en el primer gran pensador del cristianismo. De hecho, seguir la ruta que Pablo trazó sobre la antigua Grecia propició que el autor se adentrara en el pensamiento paulino, un judío fariseo que tras caer del caballo -una imagen simbólica- en el viaje a Damasco se puso al servicio del cristianismo. No en balde, las cartas paulinas son un documento fundamental para conocer la vida de las primeras comunidades cristianas como la de Corinto y, sobre todo, para adentrarse en la teología paulina que anuncia la buena nueva -evangelio- del acontecimiento de la muerte-resurrección de Cristo, una irracionalidad consciente y majestuosa. En cualquier caso, la resurrección no se trata de una verdad que los historiadores puedan comprobar, sino de una verdad existencial y de ninguna manera verificable. En último término, esta resurrección -un escándalo para la razón humana- solo se puede entender desde una posición intelectual receptiva al misterio de la palabra, a la fuerza del Logos joánico.

Palabras clave: Pablo de Tarso, filosofía de la educación, teología de la educación, historia de la pedagogía, cristianismo, pensamiento pedagógico.

\section{Paul de Tarse (10-67): j'en ai été stupéfié}

Résumé : Cet article dresse le profil de Paul de Tarse, que l'auteur n'a connu que lorsqu'il a visité Athènes en 1969. C'est à cette occasion, accompagné de sa sœur Maria, qu'il s'est rendu compte de l'ampleur du message paulinien, qui l'a stupéfié. Après s'être séparé officiellement du judaïsme, Paul est devenu sans aucun doute le premier grand penseur du christianisme. De fait, c'est en suivant le chemin tracé par celui-ci dans la Grèce antique que l'auteur a été amené à s'aventurer dans la pensée de Paul, un juif pharisien qui, après être tombé de son cheval - une image symbolique - sur la route de Damas, s'est mis au service du christianisme. Non en vain, les épîtres pauliniennes constituent un document fondamental pour connaître la vie des premières communautés chrétiennes comme celle de Corinthe et, surtout, pour découvrir la théologie paulinienne qui annonce la bonne nouvelle - l'Évangile - de l'événement de la mort-résurrection du Christ, une irrationalité consciente et majestueuse. Quoi qu'il en soit, la résurrection n'est pas une vérité que les historiens puissent vérifier, mais une vérité existentielle et en aucun cas vérifiable. En fin de compte, cette résurrection - un scandale pour la raison humaine - peut seulement être envisagée d'un point de vue intellectuel réceptif à l'égard du mystère de la parole, de la force du Logos johannique.

Mots clés : Paul de Tarse, philosophie de l'éducation, théologie de l'éducation, histoire de la pédagogie, christianisme, pensée pédagogique.

\section{Paul of Tarsus (10-67): I stood there speechless}

Abstract: This paper explores a particular aspect of the life of Paul of Tarsus that the author discovered during a visit to Athens in 1969. That year, in the company of his sister Maria, he came to realise the magnitude of Paul's message, which left him speechless. Once separated from official Judaism, Paul has doubtless become the first major thinker of Christianity. Indeed, by retracing Paul's route through Ancient Greece, the author was able to enter deeply into the thought of the apostle, a Jewish Pharisee who after falling from his horse on the road to Damascus-a symbolic image-put himself at the service of Christianity. With good reason, the Pauline epistles are fundamental to understanding the life of early Christian communities like the one in Corinth and, above all, to delving into Pauline theology, which announces the good news - the gospel-of the event of Christ's death and resurrection, a conscious and majestic irrationality. In any case, the resurrection is not a truth that historians can prove, but rather an existential truth that is in no way verifiable. Lastly, the resurrection-a scandal for human reason-can only be grasped from an intellectual position that is receptive to the mystery of the word, to the force of John's Logos.

Keywords: Paul of Tarsus, philosophy of education, theology of education, history of pedagogy, Christianity, pedagogical thought. 